\title{
ANALISIS KARAKTER TOKOH WAYANG SRIKANDI DALAM LAKON PERANG BAHRATAYUDA SEBAGAI PEMBELAJARAN KARAKTER UNTUK REMAJA
}

\author{
Delatari Miranti, Nurulfatmi Amzy \\ Program Studi Desain Komunikasi Visual \\ Fakultas Bahasa dan Seni Universitas Indraprasta PGRI \\ Jl. Nangka 58 Tanjung Barat, Jakarta Selatan, 12530 \\ delamidell@gmail.com
}

\begin{abstract}
Abstrak
Cerita pewayangan, khususnya di Indonesia sangatlah banyak dan beragam. Disetiap cerita pewayangan tersebut, ada banyak filosofi dan pesan baik yang dapat diterapkan di kehidupan sehari-hari. Contohnya, cerita wayang Srikandi dalam lakon Perang Bahratayudha. Kepribadian positif Srikandi dalam lakon ini dapat dicontoh oleh para remaja, seperti keberanian, tanggungjawab, dan berusaha keras utnuk mendapatkan apa yang ia mau. Metode yang digunakan adalah metode kualitatif, di mana penulis melakukan observasi dan wawancara kepada narasumber yang kompeten. Karakter Srikandi yang pemberani, membela kebenaran, dan pantang menyerah sesungguuhnya dapat dipelajari dan ditiru dalam kehidupan sehari-hari khususnya untuk remaja. Hal ini dapat membantu pembentukkan karakter mereka yang sesungguhnya.
\end{abstract}

Kata Kunci: Pembentukan Karakter, Srikandi, Remaja Wayang

\begin{abstract}
Puppet stories, especially in Indonesia are very many and varied. Every puppet story, there are many good philosophies and messages that can be applied in everyday life. For example, the Srikandi puppet story in the Bahratayudha War play. Positive personality Srikandi in this play can be emulated by teenagers, such as courage, responsibility, and striving to get what he wants. The method used is a qualitative method, where the author makes observations and interviews with competent speakers. Srikandi's character is brave, defends the truth, and never gives up as much as he can, can be learned and imitated in everyday life, especially for teenagers. This can help shape their true character.
\end{abstract}

Keywords: Formation of Character, Heroine, Teenager, Puppet

\section{PENDAHULUAN}

Wayang adalah kebudayaan bangsa Indonesia yang kisah-kisahnya banyak mengandung manfaat dan nilai kebaikan yang bisa diambil dan dipelajari. Salah satunya adalah karakter atau kepribadian dari Srikandi yang dapat dijadikan pembelajaran sebagai teladan khususnya bagi remaja yang masih takut untuk menunjukkan siapa dirinya dan terkekang dengan aturan yang ada.

Siapa yang tidak tahu Srikandi, tokoh wayang perempuan yang sudah tidak asing di telinga yang dikenal dengan keberanian dan keahliannya dalam memanah. Bagi penikmat wayang, Srikandi menjadi salah satu tokoh yang populer. Banyak lakon yang diperankannya, mulai dari lakon Mangguru Manah sampai dengan lakon Perang Bahratayuda. 
Dewi Wara Srikandi adalah seorang tokoh wayang yang pemberani, bersuara nyaring, keras, dan handal atau piawai dalam olah panah. Yang menjadi watak dominan dalam diri Srikandi yaitu ia bersemangat, pemberani, memiliki tekad yang kuat, dan percaya diri. Terkadang, karena rasa tahu yang besar Srikandi suka bertindak sepontan saja. Srikandi juga menjadi salah satu wanita yag memukau terutama saat ia memperjuangkan kebenaran (Puppet, 2014. www.sekarbudayanusantara.co.id. Diakses pada 25 September 2018).

Kepribadian Srikandi yang banyak mengandung dampak posistif sangat menarik untuk dianalisa, hal inilah yang menarik penulis untuk menjabarkan watak dan kepribadian Srikandi. Tujuannya agar para pembaca khususnya remaja dapat menyarik hal positif dari yang akan di jabarkan seperti karakter dan sifat baik dari Srikandi yang dapat di teladani.

\section{METODE PENELITIAN}

Penulis menyusun artikel ini menggunakan metode penelitian berupa Studi Pustaka, baik cetak seperti buku, maupun elektronik seperti blog, artikel, jurnal, dan sebagainya. Penulis juga melakukan observasi dan wawancara dengan nara sumber dengan bertanya berkaitan dengan watak dan karakter Srikandi yang sebenarnya. Yang tentunya penulis rangkum kembali dan menganalisisnya.

\section{PEMBAHASAN}

Beberapa kutipan yang penulis ambil yang menyebutkan watak maupun karakter dan kepribadian Srikandi yang selanjutnya penulis analisa juga jabarkan adalah sebagai berikut:

Mengutip dari My Bekti Blog, 2017 yang menyebutkan bahwa Srikandi adalah wanita yang memiliki tabiat seperti laki-laki, ia juga suka dengan olah panah, berperang, berkuda, dan yang lainnya. Hal ini bukan semata-mata ia lakukan untuk kesenangan melainkan bertujuan agar mampu menjaga dirinya sendiri juga menjaga orang lain dari tindak kejahatan. Dari hal ini penulis menganalisis bahwa Srikandi adalah perempuan yang pemberani, dibuktikan dari minatnya untuk belajar panahan dan menyukai peperangan dalam segi membela kebaikan. Hal ini dapat dijadikan contoh oleh para remaja yang jika kita benar dan apa yang akan kita lakukan adalah sebuah kebaikan, maka jangan pernah takut. Contohnya untuk menerapkan sifat atau karakter ini bisa diterapkan dalam hal menegakkan dan membela kebenaran seperti:

Membela teman yang menjadi korban bullying. Bullying yang berasal dari bahasa inggris Bull yang berarti banteng yang senang menyeruduk kesana-kemari. Dalam bahasa Indonesia secara etimologi bully berarti penggertak, atau orang yang mengganggu orang yang lemah (Ela, 2017. Faktor yang Mempengaruhi Remaja dalam Tindakkan Bullying. 325:330). Contoh karakter Srikandi yang bisa ditiru adalah berani dan rela berjuang dalam membela dan mengakkan kebenaran. Jika melihat atau tahu ada teman yang di bully atau bahkan kita sendiri yang mengalaminya, maka sebaiknya kita berani melawan dalam hal yang benar dan melaporkannya agar bisa ditindak dan meminimalisir kejadian yang sama terulang kembali.

Dari buku Tokoh Wayang Terkemuka Hlm. 178 yang ditulis oleh Solichin (2018) menyebutkan: Srikandi adalah putri raja Cempala yang mencapai kedudukannya dan ketenarannya bukan karena ia adalah anak seorang raja, tetapi karena Srikandi sedari remaja sudah berjuang untuk mendapatkan itu semua. Dimulai dari tekun dalam belajar segala hal sampai berani melawan musuh yang mengancam kerajaannya. Disini kita dapat melihat bahwa Srikandi adalah orang yang mau bekerja keras untuk meraih apa yang ia inginkan. Srikandi juga orang yang mau belajar. Remaja masa kini seharusnya dapat mencontoh kepribadian Srikandi ini, jika ingin mendapatkan sesuatu, maka haruslah bersungguh-sungguh dalam menggapainya.

Hal yang dilalui juga tidak mudah, harus mau belajar, berusaha, dan bekerja keras untuk mendapatkan apa yang diinginkan. Contohnya saja mendapatkan nilai yang baik, untuk hal ini kita tidak hanya mencari cara cepat untuk mendapatkan nilai yang maksimal seperti melakukan tindakkan yang tidak baik seperti mencontek agar nilai bisa lebih bagus. Jika ingin mendapatkan hal seperti itu, kita haruslah mau belajar agar pintar, sehingga dapat meraih apa yang kita inginkan. 
Dalam buku ini juga dijelaskan bahwa Srikandi adalah pelopor perjuangan Emansipasi Wanita. Dimana pada buku ini dijelaskan bahwa Srikandi tidak ingin derajat wanita direndahkan. Kutipan yang penulis ambil dari buku yang sama yang mengatakan bahwa Srikandi merasa derajat wanita masih direndahkan, banyak wanita yang tidak bisa memilih jalan hidupnya sendiri. Seperti kakaknya Dewi Drupadi yang dijodohkan melalui sayembara, yang dimana sayembara ini dimenangkan oleh pandawa. Kekecewaan Srikandi bermula dari sini meskipun Srikandi tahu bahwa kakaknya senang diboyong ke negri Amarta menjadi istri Puntadewa.

Namun ia berfikir kalau dirinyapun pasti mendapatkan perlakuan yang sama kelak dijodohkan dengan orang yang belum tentu ia cintai. Srikandi merasa saat itu bahwa wannita tidak diperbolehkan menentukan pilihannya sendiri seperti kakaknya yang dihadapkan dengan keputusan tanpa pilihan. Dari sinilah Srikandi mulai membuktikan bahwa wanita juga seharusnya memiliki kebebasan dan kesetaraan (Solichin, (2018). Hal. 178:180).

Ketika hati dan fikiran Srikandi di penuhi dengan perasaan yang meresahkannya ini, kemudian sang guru Dewi Saraaswati datang dan mengatakan jika Srikandi ingin memperjuangkan haknya sebagai wanita, berjuang untuk emansipasi wanita, maka Srikandi disarankan untuk menjadi wanita yang cerdas dan juga berani. Srikandi tidak dianjurkan untuk berpangku tangan pada kehidupan yang mewah, ia harus belajar berbagai ilmu pengetahuan dan keterampilan (Solichin, (2018). Hal. 180). Ilmu pengetahuan sesungguhnya menjadi sarana yang dapat membuat wanita jadi mandiri, tidak bergantung pada orang lain dan justru bisa membantu dan mensejahterakan orang lain. Inilah alasan mengapa wanita juga perlu pendidikan, belajar, dan memiliki keterampilan. Karena tangan di atas lebih baik daripada tangan yang menengadah. (Solichin, (2018). Hal. 180).

Mendengar nasehat dari gurunya, Srikandi segera keluar dari istana untuk belajar berbagai ilmu pengetahuan dari gurur-guru yang mumpuni. Srikandi belajar dengan tekun dan giat, hal ini membuatnya menjadi wanita yang pandai, tidak hanya ilmu pengetahuan Srikandi juga mampu menguasai ilmu perang. Ia piawai dalam olah panah berkat gurunya Arjuna yang kelak menjadi suaminya itu. Kemandirian dan keberaniannya ini juga terbukti dalam lakon Mnagguruh Manah, dimana saat itu Srikandi ingin dipersunting oleh Prabu Jungkung Mardeya yang lamarannya diterima oleh sang ayah. Namun, dengan sikap tegas dan beraninya Srikandi menolak perjodohan tersebut karena ia tidak mencintai sang prabu. Srikandi tetap memiliih Arjuna untuk menjadi suaminya.

Meskipun hal ini menyebabkan konflik yang tajam, dengan keteguhan hati Srikandi dapat melwatinya, dan iapun benar-benar sudah menjadi wanita yang mandiri yang dapat berpijak dan menentukan pilihannya sendiri.ia tumbuh menjadi pribadi yang mandiri karena bekal pengetahuan serta keberanian yang ia miliki. Martabatnyapun meningkat tidak saja karena ia seorang putri raja, tetapi lebih kepada kualitasnya (Solichin (2018). Hal. 183).

Analisi karakter yang penulis dapat sebagai contoh untuk dipelajari oleh para remaja khususnya wanita yaitu:

\section{Tidak puas diri atau tidak sombong}

Hal ini terbukti dari kepribadiannya yang rendah hati dan tidak merasa berkuasa padahal ia adalah anak seorang raja yang cukup ternama dikerajaannya itu. Srikandi tetap berusaha dengan kemampuannya sendiri. Ia tidak berpangku tangan atas apa yang sudah ia miliki, karna ia sadar semua itu hanya milik orang tuanya dan juga titipan. Oleh karena itu, Srikandi tetap rendah hati, tidak pernah puas diri dalam hal apa yang sudah ia miliki hanyalah titipan, ia akan terus mencari apa yang bermanfaat untuk dirinya.

Kepribadian Srikandi ini layak untuk dijadikan contoh khususnya untuk para remaja. Jangan berpuas diri dengan apa yang kalian miliki, apalagi menjadi pasif karna sudah terbiasa memiliki kehidupan yang enak dari orang tua. Hal ini tidak akna membuat kita berkembang dan maju, kita akan terhenti pada titik itu saja. Membanggakan apa yang bukan hasil dari jeripayah kita sendiri adalah hal yang tidak baik. Srikandi, tetap rendah hati meskipun ia pintar dan memiliki apa yang ia butuhkna, ia tetap mau berjuang untuk mendapatkan yang lebih baik lagi. Tentunya 
hal ini lah yang harusnya kita pelajari dan jadikan contoh agar mendapatkan hidup yang berkualitas.

\section{Memiliki tekad yang kuat}

Dijelaskan di atas bahwa Srikandi memiliki tekad yang kuat, ia ingin bahwa wanita tidak di pandang sebelah mata dan mendapatkan derajat yang sama. Ia tidak hanya sekedar berangan namun benar-benar membuktikannya. Jika ia ingin sesuatu maka ia membulatkan tekad untuk menggapainya, Srikandi bukanlah wanita lemah yang mudah menyerah. Srikandi tau jika ingin menggapai sesuatu maka ia harus benar-benar tetap pada pendiriannya.

Memiliki tekad yang kuat adalah ciri dari orang yang kelak akan menjadi sukses. Karena tekad yang kuat dapat mendorong orang menjadi semnagat untuk menggapai apa yang ia inginkan. Kepribadian Srikandi ini hendaknya dapat dicontoh oleh para remaja, bukan hanya wanita tetapi pria pun juga harus memiliki tekad yang kuat dalam kebaikan pastinya. Karena mencapai sesuatu yang diinginkan itu tidak mudah dan cepat, oleh karena itu tekad harus lah selalu menjadi pendukung utama untuk menggapainya.

Memiliki tekad yang kuat untuk meraih prestasi misalnya, adalah bentuk sederhana yang dapat memicu kita untuk tetap mengerjakan hal-hal positif dengan sungguh-sungguh dan akan membuat kita tetap fokus untuk meraihnya. Karena jika tekadnya saja sudah lemah, bagaimana caranya kita dapat melangkah untuk meraih sukses.

\section{Bekerja keras}

Berhubungan dengan tekad, niat yang kuat untuk mendapatkan apa yang kita inginkan juga harus diiringi dengan usaha yang kuat juga. Bekerja keras untuk mendapatkan apa yang diinginkan ada para diri Srikandi. Srikandi bukanlah wanita yang malas, ia tahu bahwa keinginannya untuk memperjuangkan emansipasi bukanlah hal yang mudah, oleh karenanya ia mengusahakan segala sesuatu untuk menggapainya.

Bekerja keras menurut Muzdalifah dalam Elfindri, dkk. (2012) hal. 102 adalah sifat seseorang yang tidak mudah berputus asa dalam apa yang ingin ia gapai yang tentunya disertai dengan usaha yang sungguh-sungguh dalam menggapainya. Orang dengan karakter ini biasanya memaksimalkan kemampuannya semaksimal mungkin dalam mengerjakan tugas atau pekerjaannya. Dan orang yang memiliki karakter bekerja keras ini juga selalu di dampingi dengan fikiran yang positif sehingga tidak mudah dipatahkan oleh rintangan yang akan dihadapinya.

Karakter seperti inilah yang sangat di butuhkan oleh remaja, masalahnya di era ini banyak remaja yang mundur sebelum berjuang contohnya saja mahasiswa pada tingkat akhir. Banyak dari mereka yang menunda bahkan gugur karna kalah sebelum berperang. Tidak adanya tekad yang kuat dan usaha membuat semua hal menjadi sulit. Orang-orang yang memiliki karakter bekerja keras ini sangatlah mumpuni untuk meraih kesuksesan. Karena seperti dijelaskan di atas, mereka yang bekerja keras adalah mereka yang tetap tegar dan berjuang tidak mudah di patahkan oleh rintangan yang ada. Jika remaja Indonesia memiliki karakter ini niscaya bangsa ini akan menjadi bangsa yang lebih maju dan memiliki bibit-bibit unggul yang mampu bersaing di era global.

\section{Cerdas}

Cerdas berbeda dengan pintar, menurut kutipan yang penulis ambil dari sahabatnestle.co.id, cerdas berbeda dengan pintar yang membutuhkan proses. Cerdas merupakan anugrah bawaan dari Tuhan YME, semua orang memiliki kecerdasannya masing-masing. Cerdas adalah orang yang sering berimprovisasi dan lebih kreatif dalam melakukan sesuatu. Kemampuan berfikir orang cerdas sangatlah cepat, sehingga ia mudah tanggap, mengerti, dan lebih mudah memahami apa yang dimaksud. Menurut Kamus Besar Bahasa Indonesia (2001) ornag cerdas tidak terpaku dengan teori, namun lebih terhadap pemahaman konsep.

Bagi ornag cerdas senjata utamanya adalah logika, dan pengetahuan yang ia dapat dari teori hanyalah pendukung. Seperti halnya Srikandi, ia tidak hanya menguasai ilmu pengetahuan saja tetapi ia mampu menguasai ilmu di berbagai bidang misalnya saja olahraga. Seperti penguasaanya 
pada olah panah membuat Srikandi unggul dari wanita lain, selain cerdas di ilmu pengetahuan yang ia dapatkan dari berbagai guru yang mumpuni. Kemampuannya yang cepat tanggap mempermudah Srikandi dalam menyerap pelajaran-pelajaran yang ia terima dari para gurunya membuat ia menjadi wanita yang mandiri dan cerdas.

Kepribadian ini juga seharusnya dijadikan contoh, kita sebagai manusia sudah dianugerahkan kecerdasa oleh Tuhan, tinggal seberapa cerdas pula kita utnuk mengasahnya. Kecerdasan pada remaja seharusnya digali dan dibiarkan berkembang agar bisa mnejadi sesuatu yang berguna. Memiliki kecerdasan adalah nilai unggul terutama pada remaja. Hal ini dapat membantunya meraih impian.

\section{SIMPULAN}

Pewayangan bukan hanya pentas drama yang hanya dapat disaksikan saja, namun jika kita paham dan mengerti bahwa setiap tokoh dalam cerita pewayangan ini memiliki nilai positif yang dapat diambil dan dipelajari. Seperti yang penulis analisa dan jabarkan diatas, karakter Srikandi yang cerdas, pantang menyerah, memiliki tekad yang kuat dan yang lainnya bisa dijadikan contoh bagi para remaja, bahwa setiap diri manusia itu memiliki nilai kebaikan yang patut ditunjukkan. Karena kepribadian yang baik akan membawa dampak yang baik bagi diri sendiri maupun orang lain.

Jika kita melihat seni pertunjukkan wayang, jangan berfikir bahwa pertunjukkan tersebut membosankan, tapi manfaat apa yang kita bisa dapatkan dari menonton pertunjukkan wayang tersebut. Banyak hal positif yang dapat kita ambil dari kesenian ini. Baik dari cerita, pesan moran, dan bahkan karakter pada setiap tokoh wayang adalah sebuah pembelajaran untuk kita agar bisa menilai diri sendiri apakah sudah baik atau belum. Dan tentunya juga dapat dijadikan contoh dan diterapkan pada kehidupan sehari-hari nilai-nilai positif yang bisa kita ambil dari cerita dan karakter wayang tersebut.

\section{DAFTAR PUSTAKA}

Bekti. (2017). Tokoh Pewayangan (Dewi Srikandi). [Online]. Diakses dari http://www.mybektiblog.woopress.com/2017/03/26/tokoh-pewayangan-dewi-srikandi/

Zakiyah, E. Z., Humaedi, S., \& Santoso, M. B. (2017). Faktor yang mempengaruhi remaja dalam melakukan bullying. Prosiding Penelitian dan Pengabdian kepada Masyarakat, 4(2), 324-330.

Muzdalifah, A. (2013). Peningkatan kerja keras dan prestasi belajar IPA materi bagian tubuh tumbuhan melalui metode discovery strategy di kelas IV Sd Negeri 08 Bantarbolang. Skripsi. Program Studi Pendidikan Guru Sekolah Dasar, Fakultas Keguruan dan Ilmu Pendidikan, Universitas Muhammadiyah Purwokerto.

Nusantara, S. B. (2014). Srikandi. [online]. Diakses dari http://sekarbudayanusantara.co,id/ Wynk/?p=1154

Solichin. (2018). Tokoh wayang terkemuka. Jakarta: Yayasan Sena Wangi 